\title{
Surgical repair of congenital mitral valve malformations in infancy and childhood: A single-center 36-year experience
}

\author{
Giovanni Stellin, MD, ${ }^{\text {a }}$ Massimo A. Padalino, MD, $\mathrm{PhD},{ }^{\text {a }}$ Vladimiro L. Vida, MD, $\mathrm{PhD},{ }^{\text {a }}$ \\ Giovanna Boccuzzo, MPH, ${ }^{\mathrm{b}}$ Emanuele Orrù, MD, ${ }^{\mathrm{a}}$ Roberta Biffanti, MD, ${ }^{\mathrm{c}}$ Ornella Milanesi, MD,${ }^{\mathrm{c}}$ and \\ Alessandro Mazzucco, $\mathrm{MD}^{\mathrm{d}}$
}

Objective: We sought to evaluate the results of surgical repair and determine predictors for the late outcome of congenital mitral valve dysplasia.

\begin{abstract}
Methods: Preoperative, operative and postoperative data were obtained from an institutional database; follow-up data came from regular clinical evaluation at our institution or elsewhere. Patients were divided into isolated and complex cases according to the complexity of associated lesions.
\end{abstract}

Results: Between 1972 and 2008, 93 patients (43 male and 50 female patients) underwent mitral repair (median, 4.5 years; range, $0.16-19.8$ years). Predominant mitral regurgitation was present in $52 \%$. Associated cardiac anomalies were present in $72 \%$. Sixty-one patients were in the complex group. All patients underwent successful mitral repair. Surgical repair was tailored to the patient's valve anatomy. Early death was $7.5 \%$. The postoperative course was uneventful in $86 \%$ of patients. At a mean follow-up of 10.3 years (median, 8.4 years; completeness, $94 \%$ ), late mortality is $8 \%$ (7 patients). Twelve patients underwent mitral reintervention (11 replacements and 1 repair). Among the 80 survivors, $82.5 \%$ were in New York Heart Association class I or II, and $61.2 \%$ had some degree of persistent mitral regurgitation or stenosis, despite stable hemodynamics. Stenosis is a statistically significant risk factor for surgical intervention at less than 1 year of age and is related to higher overall mortality and incidence of late cardiac failure and mitral dysfunction; parachute mitral valve is related to higher mortality and morbidity.

Conclusions: Mitral valve repair shows acceptable early mortality and reoperation rates. Mitral malformations in the complex group are related to a significantly higher risk of reoperation on the mitral valve. Parachute mitral valve is associated with a higher rate of early mortality. (J Thorac Cardiovasc Surg 2010;140:1238-44)

Earn CME credits at

http://cme.ctsnetjournals.org

Congenital mitral valve (CMV) dysplasia is a relatively rare and highly complex cardiac malformation that presents with a wide variety of morphologic abnormalities, as well as a high incidence of associated intracardiac anomalies. ${ }^{1-3}$ Surgical repair of CMV anomalies has represented a major therapeutic challenge, the approach to which has significantly evolved, as reported by various authors. ${ }^{4-8}$ Valve repair rather than replacement for CMV dysplasia has been advocated over the years by us and others, ${ }^{4-6}$

From the Pediatric and Congenital Cardiac Surgery Unit, ${ }^{\mathrm{a}}$ the Department of Statistics, ${ }^{b}$ and the Department of Pediatrics, ${ }^{c}$ University of Padua Medical School, Padua, Italy; and the Department of Cardiac Surgery, ${ }^{\mathrm{d}}$ University of Verona, Medical School, Verona, Italy.

Disclosures: None.

Received for publication Nov 15, 2009; revisions received March 16, 2010; accepted for publication May 16, 2010; available ahead of print June 16, 2010.

Address for reprints: Massimo A. Padalino, MD, PhD, Pediatric and Congenital Cardiac Surgery Unit, Centro V Gallucci, Via Giustiniani, 2, 35128 Padova, Italy (E-mail: massimo.padalino@unipd.it).

0022-5223/\$36.00

Copyright (c) 2010 by The American Association for Thoracic Surgery doi:10.1016/j.jtcvs.2010.05.016 mostly because of the untoward deleterious effects of prosthetic valve replacement, particularly in small children.

We report our 36-year experience with surgical treatment of CMV disease, with particular attention to the long-term performance of the reconstructed mitral valve (MV), as well as to the effects of associated intracardiac lesions, which might influence long-term results after repair.

\section{MATERIALS AND METHODS}

All consecutive patients affected by CMV dysplasia referred to our center and scheduled for surgical repair between October 1972 and January 2008 were included. Exclusion criteria were the association with atrioventricular septal defects, hypoplastic left heart syndrome, or other types of functional single-ventricle anomalies and MV prosthetic replacement as the first operation. According to Carpentier's physiopathological classification, ${ }^{9}$ patients were divided into 2 groups: group I, patients with CMV regurgitation or prevalent mitral regurgitation (MR); group II, patients with MV stenosis (MS) or prevalent MS. To evaluate the clinical importance of the associated cardiac abnormalities, the patients were further arbitrarily subdivided into 2 subgroups according to the severity of the associated intracardiac anomalies rather than the anatomic severity of the dysplastic MV itself: isolated group, when any anatomic type of CMV dysplasia was isolated or in association with "simple" intracardiac lesions, such as an atrial septal defect or a patent ductus arteriosus; complex group, when any type of CMV dysplasia (regardless for its anatomopathological severity) coexisted with other malformations, such as aortic isthmic coarctation, aortic or subaortic stenosis, or ventricular septal defects. 

Abbreviations and Acronyms
$\mathrm{CI}=$ confidence interval
$\mathrm{CMV}=$ congenital mitral valve
$\mathrm{MR}=$ mitral regurgitation
$\mathrm{MV}=$ mitral valve
NYHA $=$ New York Heart Association
$\mathrm{OR}=$ odds ratio

Review of medical records and computerized hospital data was approved by our University Hospital Committee on Clinical Investigation, and the procedures followed were in accordance with institutional guidelines for retrospective record review and protection of patient confidentiality. The need for patient consent was waived.

Follow-up was based on clinical and instrumental data derived from records of the outpatient clinic of the Department of Pediatrics of the University of Padua, where most patients were clinically evaluated on a regular basis. However, those patients who were followed elsewhere were contacted by telephone, and clinical and instrumental data were provided by the referring cardiologist after obtaining consent.

Early and late-term outcomes were evaluated according to early (within 30 days or in the hospital) and late mortality, freedom from reoperation (either any cardiac operation or specifically redo operation on the MV), and clinical conditions, expressed as New York Heart Association (NYHA) functional class (I-IV), need for chronic cardiac medications, presence or absence of sinus rhythm, and hemodynamically significant residual valve defects. Hemodynamic significance was as follows: MR if flow convergence region ${ }^{10}$ was greater than $100 \mathrm{~mL} \cdot \mathrm{min}^{-1} \cdot \mathrm{m}^{-2}$ and MS if transmitral velocity was greater than $1.3 \mathrm{~m} / \mathrm{s}$.

Descriptive and multivariate analyses were applied to the outcomes (mortality, need for drug treatment, reoperation, need for surgical intervention on the MV before 1 year of age, hemodynamic stability, and sinus rhythm) to establish the effect of the following risk factors: age, sex, complex case, MV stenosis, parachute MV, need for surgical intervention on the MV before 1 year of age, and cleft MV. Age is expressed as a continuous variable, with median, mean, and standard deviation. The remaining variables are dichotomous. The relationship between every outcome and a single dichotomous risk factor was calculated by using the Fisher exact test when frequencies were less than 5 and by using the $\chi^{2}$ test when expected frequencies were greater than 5 . The statistical significance was assumed by using a cutoff threshold of a $P$ value of .05 . Moreover, every outcome was related to several risk factors by means of a logistic regression model, in which the significant incremental (odds ratio $[\mathrm{OR}]>1$ ) or decremental $(\mathrm{OR}<1)$ risk factors were identified by means of a stepwise selection method.

Because of the very long period of recruitment, time was considered an explanatory variable. In this way the multivariate analysis provides the importance of the risk factors' net of a potential time effect. After several tests, the most efficient use of the time variable was as a dichotomous one: a first period from 1972 to 1984 and a second period from 1985 to 2008.

Kaplan-Meier analysis was used to evaluate freedom from death and reoperation for different groups (MS vs MR and isolated vs complex) and different preoperative conditions, such as mitral anatomy.

Statistical analyses were performed with SPSS (SPSS, Inc, Chicago, Ill) and SAS (SAS Stat 9.1; SAS Institute, Inc, Cary, NC) statistical software.

\section{RESULTS}

Between October 1972 and January 2008, 96 consecutive patients affected by CMV dysplasia underwent surgical intervention at our institution. Among these, 3 patients in our early experience (before January 1985) underwent MV replacement with a prosthesis as a primary treatment because of an initially different surgical philosophy in approaching severe CMV malformations at that time. Thus 93 patients were treated with primary CMV repair and are the object of this study.

The median age at the time of the operation was 4.5 years (mean, $5.8 \pm 4.9$ years); $13(14 \%)$ patients were younger than 12 months. Since January 1991, all patients were given diagnoses based on exclusive, preoperative, routine 2-dimensional echocardiographic examination, during which cardiac catheterization was performed as a primary or complementary instrument for diagnosis before 1991, accounting for $44.1 \%$ of the diagnoses.

Twenty (26.8\%) patients presented clinically with dyspnea and 10 with failure to thrive, whereas 5 patients were admitted on an emergency basis in cardiogenic shock on mechanical ventilation and inotropic drugs. The remaining patients had either mild or no symptoms. The cardiothoracic ratio on plain radiographic analysis was greater than 0.5 in $52(56 \%)$ patients. According to Carpentier's classification, ${ }^{9} 48(51.6 \%)$ patients presented with MR or prevalent MR, whereas the remaining 45 (48.4\%) had MS or prevalent MS (Table 1). ${ }^{9}$ Preoperative pulmonary mean arterial pressure was available in 22 patients of those submitted to cardiac catheterization, and it was $37 \mathrm{~mm} \mathrm{Hg}$ (range, 16-60 mm Hg).

Associated cardiac anomalies were found in $67(72 \%)$ cases. According to the abovementioned subdivision, 32 $(34.4 \%)$ patients were in the isolated group, whereas 61 $(65.6 \%)$ were in the complex group. Thirty patients had undergone a previous cardiac procedure, either surgical or interventional (Table 2).

All patients were submitted to successful MV repair. Various surgical techniques were used, as previously reported, ${ }^{4,5}$ according to the surgeon's preference, the different cardiac pathological anatomy, and the different period. As a general rule, each operation was tailored to the peculiar anatomy of each type of CMV dysplasia. Surgical techniques and data are summarized in Table 3.

Significant complications occurred in $14(15 \%)$ patients and are summarized in Table 4. Early mortality was $7.5 \%$ (7 patients). Main causes of death were low cardiac output syndrome in 4 patients, hemorrhagic shock in 2 patients, and mediastinitis in 1 patient (Table 4). Five (71\%) patients died before January 1984 . There were only 2 early deaths among 68 subsequent consecutive patients undergoing operations after 1984 and no deaths since March 2002.

Of the 13 patients who required surgical treatment within the first year of life, $86 \%$ (11 patients) had MS, and $86 \%$ (11 patients) were in the complex group. There were 2 early deaths $(15.4 \%)$.

\section{Follow-up}

Of the 86 surviving patients, 6 live abroad and were lost to follow-up. Late follow-up was available for the remaining 
TABLE 1. Types of CMV dysplasia according to Carpentier's classification $^{9}$

\begin{tabular}{lc}
\hline MV malformations & No. of patients \\
\hline MV regurgitation (or prevalent) & 48 \\
Type I (normal leaflet motion) & 32 \\
Annular dilatation & 12 \\
Cleft anterior leaflet & 18 \\
Leaflet defect & 2 \\
Type II (leaflet prolapse) & 9 \\
Elongated chordae & 9 \\
Type III (restricted leaflet motion) & 7 \\
Type A (normal papillary muscles) & \\
Papillary muscles commissure fusion & 1 \\
Short chordae & 2 \\
Type B (abnormal papillary muscles) & \\
Parachute MV & 2 \\
Hammock MV & 2 \\
MV stenosis (or prevalent) & 45 \\
Type A (normal papillary muscles) & 24 \\
Papillary muscle commissure fusion & 14 \\
Supravalvular membrane & 7 \\
Double-orifice MV & 3 \\
Type B (abnormal papillary muscles) & 21 \\
Parachute MV & 10 \\
Hammock MV & 4 \\
Shone complex & 5 \\
Arcade MV & 2 \\
Total & \\
\hline$C M V$ Congenital mitral valve; $M V$, mitral valve. & \\
& \\
&
\end{tabular}

80 patients. The mean follow-up time was $10.3 \pm 9.3$ years (median, 8.4 years; range, $0.5-36.4$ years). Late mortality occurred in 7 (8\%) patients; death was cardiac related in 6 patients and was caused by chronic congestive heart failure in 5 patients and prosthetic valve thrombosis in 1 patient who had required late prosthetic replacement of the initially preserved MV.

Sixteen $(18.4 \%)$ patients required reoperations. These were on the MV in 12 patients: 7 had residual MS, and 5 had residual MR. The mean interval between the first procedure and reoperation was 4.9 years (range, 2.2 months to

TABLE 2. List of patients with associated cardiac anomalies in the complex group and those in whom repair of cardiac anomaly was performed before MV repair

\begin{tabular}{lcc}
\hline Cardiac anomaly & No. of patients & $\begin{array}{c}\text { Patients with previous } \\
\text { surgical intervention }\end{array}$ \\
\hline Subaortic stenosis & 31 & 7 \\
VSD & 23 & 0 \\
Aortic coarctation & 19 & 19 \\
Aortic regurgitation & 4 & 0 \\
Pulmonary stenosis & 3 & 2 \\
Abnormal LAD origin & 2 & 0 \\
Other & 11 & $2^{*}$ \\
\hline MV, Mitral valve; $V S D$, ventricular septal defect; $L A D$, left anterior descending. *Two \\
patients had patent ductus arteriosus closure at birth.
\end{tabular}

TABLE 3. Surgical techniques used to achieve mitral valve repair

\begin{tabular}{lc}
\hline \multicolumn{1}{c}{ Technique } & No. of patients \\
\hline Papillary muscle splitting & 35 \\
Cleft closure & 21 \\
Annuloplasty (Kaye, Paneth) & 20 \\
Supravalvular ring excision & 16 \\
Commissurotomy & 15 \\
Chordal shortening & 9 \\
Ring annuloplasty & 6 \\
Commissuroplasty & 4 \\
Accessory orifice closure & 2 \\
\hline
\end{tabular}

19.2 years). MV replacement was necessary in 11 patients (a mechanical prosthesis in 10 and a biological valve in $1 \mathrm{fe}-$ male patient). In 1 patient with a typical Shone's complex with a parachute MV (complex group), a successful MV rerepair (papillary muscle resplitting procedure) was possible 12.4 years after the initial operation because of significant residual MS. The remaining 4 redo procedures included a permanent pacemaker implantation for intermittent complete atrioventricular block in 2 cases ( 0.03 and 22.6 months after MV repair, respectively), a modified Konno operation 36.9 months postoperatively in 1 patient, and a subaortic ridge resection 39.4 months after the initial repair in another patient.

At a mean follow-up of $10.3 \pm 9.3$ years, $65(81.25 \%)$ patients are in NYHA class I or II, and $15(18.75 \%)$ patients are symptomatic with fatigue and reduced effort tolerance and are therefore in NYHA class III or IV. Three of the latter are under evaluation for elective reoperation (1 patient with MS caused by an MV arcade, 1 with a biological prosthesis implanted 19 years after CMV repair for a parachute MV, and 1 with MS in a Shone's complex). Seventy $(87.5 \%)$ patients are in stable sinus rhythm, and $10(12.5 \%)$ patients have cardiac arrhythmias: 4 required a pacemaker for postoperative atrioventricular conduction block, 4 have chronic atrial fibrillation, and 2 have ectopic atrial rhythm.

Thirty-four $(42.5 \%$ ) patients require oral medications (angiotensin-converting enzyme inhibitors, diuretics, and warfarin). Two-dimensional echocardiographic analysis at the time of last follow-up has shown absent or minimal residual MV dysfunction in $30(38.5 \%)$ patients, whereas $50(62.5 \%)$ patients presented with a hemodynamically significant

TABLE 4. List of patients with early postoperative complications that led to early death

\begin{tabular}{lcc}
\hline \multicolumn{1}{c}{ Complications } & No. of patients & Exitus \\
\hline LCO syndrome & 4 & 4 \\
Bleeding & 4 & 2 \\
Complete AV block & 2 & 0 \\
Pericardial effusion & 1 & 0 \\
Pleural effusion & 1 & 0 \\
Mediastinitis/septic shock & 1 & 1 \\
Postpericardiotomy syndrome & 1 & 0 \\
\hline
\end{tabular}

$L C O$, Low cardiac output; $A V$, atrioventricular. 


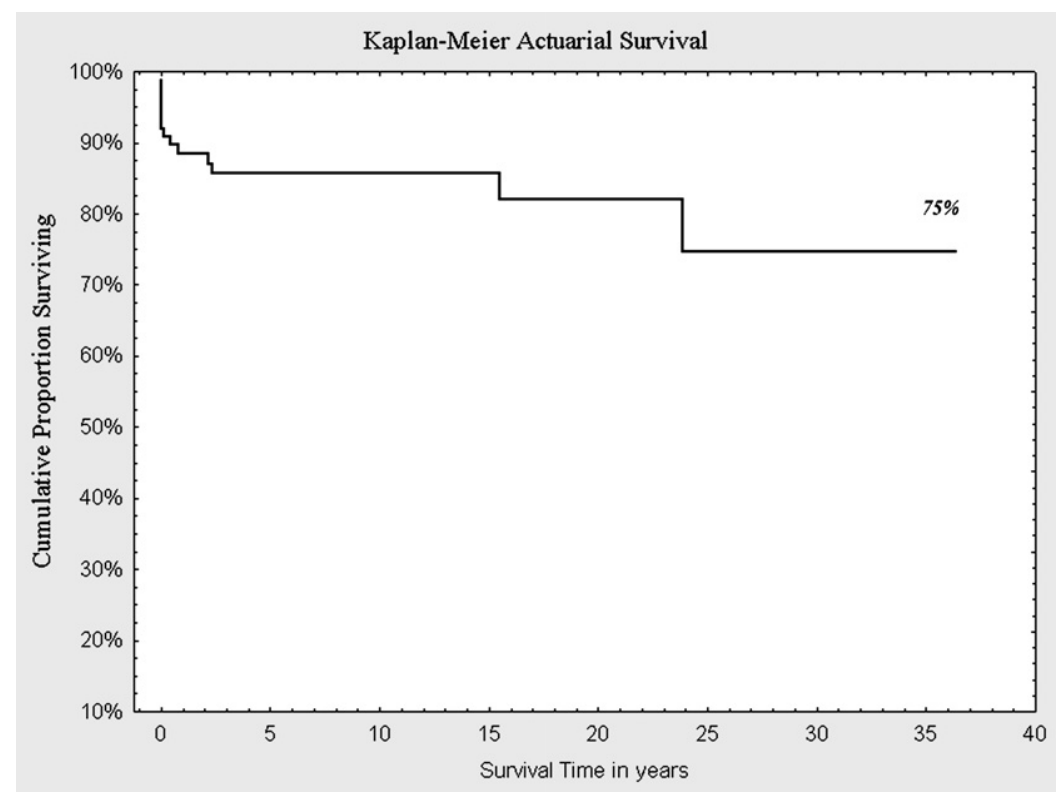

FIGURE 1. Kaplan-Meier analysis shows that overall survival is $75 \%$ at 36 years.

residual valve dysfunction (residual MS in 28 patients and MR in the remaining 22 patients). Among those 11 survivors who had undergone operations within the first year of life, 2 died late, accounting for an overall mortality in this small subgroup of $30.8 \%$. Reoperations were required in $27.3 \%$.

\section{Statistical Analysis}

Survival curves according to Kaplan-Meier analysis are shown in Figures 1 to 3. Overall survival is $75 \%$ at 36 years (Figure 1). Freedom from reoperation on the MV is $77 \%$ at 36 years (Figure 2). The survival estimate for patients with MS is significantly lower than for patients with
MR $(P=.021 ;$ OR, 4.698; Figure 3$)$. Although survival estimates for patients with complex lesions appear to be lower than in the isolated group, this proved to be not statistically significant $(P=.21)$.

The descriptive analysis of risk factors shows the following:

- Male sex has a greater incidence of complex MV disease (OR, 6.167; 95\% confidence interval [CI], 2.167-17.542) and MS (OR, 2.429; 95\% CI, 1.026-5.748). In addition, complex CMV disease and MS are strictly related $\left(\chi^{2}=4.93, P=.0263\right)$.

- Concerning freedom from reintervention on the MV, there was no statistically significant difference between

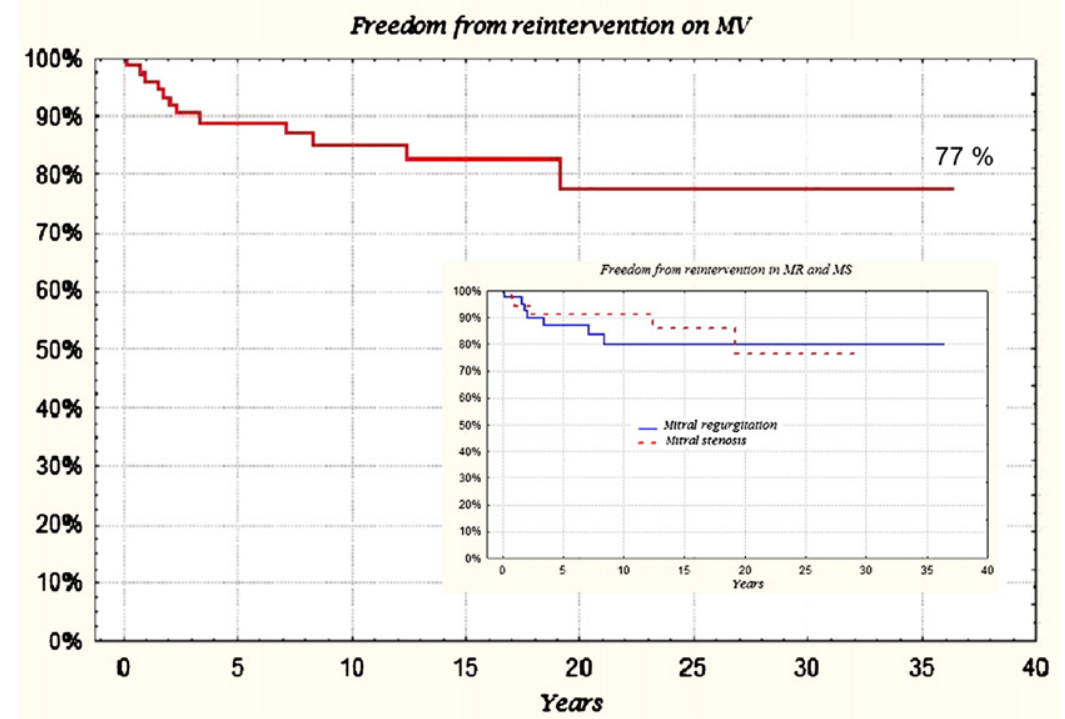

FIGURE 2. Kaplan-Meier analysis shows that freedom from reoperation on the mitral valve is $77 \%$ at 36 years. 


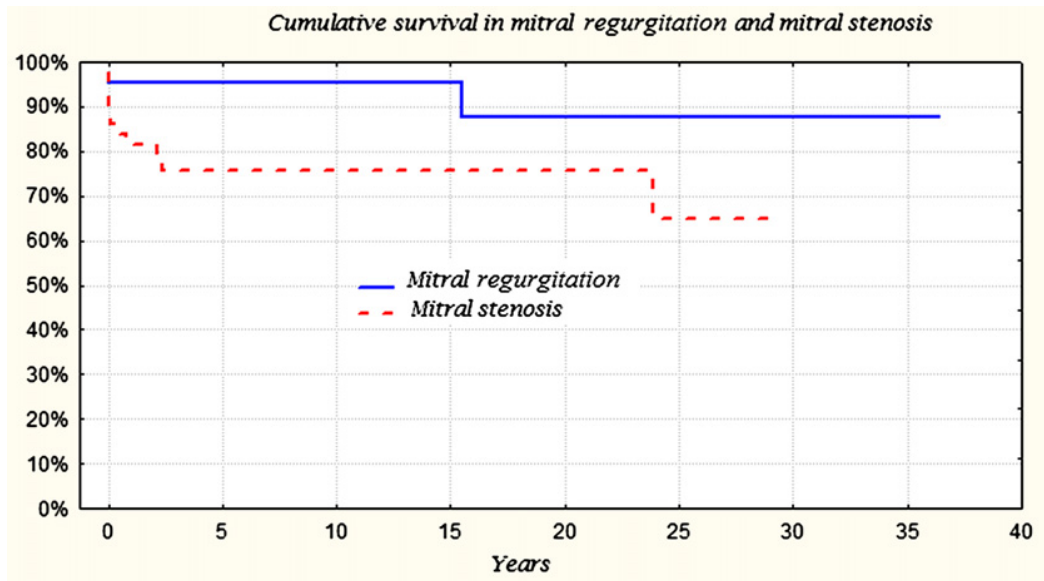

FIGURE 3. Kaplan-Meier analysis shows that survival estimates for patients with mitral stenosis are significantly lower than for patients with mitral regurgitation $(P=.021 ;$ OR, 4.698).

MS and MR and the complex versus isolated groups, but the MS group was at higher risk for late heart failure $(P=.026 ; \mathrm{OR}, 3.870)$ and persistence of MV dysfunction (defined as above: $P=.049$; OR, 2.545).

- At follow-up, a parachute MV was significantly associated with a worse late clinical outcome (NYHA class III and IV: $P=.037$; OR, 5.545).

- Persistence of MV dysfunction was significantly increased in those patients who had undergone CMV repair within their first year of life $(P=.046)$.

Logistic regression analysis is shown in Table 5 and demonstrates the following:

- MS proved to be a significant risk factor for early operation (within the first year of life: OR, 7.219; 95\% CI, 1.494-34.88) but not for early or late death (OR, 6.973; 95\% CI, 0.0802-80.6). Even if stenosis, considered alone, is significant for death, it is no longer significant at multivariate analysis, when many risk factors are considered at the same time. In this case parachute MV and age are significant risk factors for early death, and they are related with MS. When parachute MV and age are considered in the analysis, MS turns out to have a less significant effect on survival because patients with MS are younger $(P=.0015)$ and have parachute MV $(P=.026)$.

- There was no significant difference between the isolated and complex groups in early need for surgical intervention or early and late mortality; however, the complex group had a significantly higher risk for presenting with unsatisfactory outcomes at follow-up (OR, 3.173; 95\% CI, 1.158-8.693).

- A parachute MV is an important risk factor for late reoperation on the MV (OR, 6.817; 95\% CI, 1.578-29.457), late heart failure (OR, 6.1; 95\% CI, 1.309-28.420), and loss of sinus rhythm (OR, 6.377; 95\% CI, 1.10736.737). Also, residual stenosis of a parachute MV was a more common finding $(P=.0264$, Fisher exact test).

Finally, because our time frame of follow-up evaluation was quite wide, our statistical analysis was aimed at identifying the effect of time on early and late outcomes. As a result, we were able to demonstrate increased risk factors (18- and 4.7-fold, respectively) for early death and loss of sinus rhythm in those patients who underwent surgical repair before 1984 .

TABLE 5. Significant risk factors for several outcomes at logistic regression analysis

\begin{tabular}{|c|c|c|c|c|c|}
\hline \multirow[b]{2}{*}{ Outcomes } & \multicolumn{5}{|c|}{ Variables } \\
\hline & Complex MV (OR) & MV stenosis (OR) & Parachute MV (OR) & Before 1984 (OR) & Age, y (OR) \\
\hline Any adverse outcome & 3.173 & 2.520 & - & - & - \\
\hline Early death & - & & 7.122 & 18.40 & 0.636 \\
\hline Late death & - & 6.973 & - & - & - \\
\hline Preoperative medical therapy & - & - & 4.889 & - & - \\
\hline Reoperation on MV & - & - & 6.817 & - & - \\
\hline Operation on MV before $1 \mathrm{y}$ of age & - & 7.219 & - & - & - \\
\hline Heart failure at follow-up & - & - & 6.100 & - & - \\
\hline Arrhythmias & - & - & 6.377 & 4.744 & - \\
\hline
\end{tabular}

Variables significant at a level of $.05<P<.1$ are shown in italics. $M V$, Mitral valve; $O R$, odd ratio. 


\section{DISCUSSION}

This report reviews our 36-year experience with surgical management of CMV dysplasia. To the best of our knowledge, this series represents the largest cohort of patients who underwent MV repair for MV dysplasia, including long-term follow-up data.

This rare entity, which often coexists with other complex lesions of the left heart, continues to present a significant surgical challenge. Many authors have reported a significant incidence of unsatisfactory outcomes, especially in infancy, because of the complexity of the CMV anatomy, the frequent association with other heart defects, and a relative paucity of patients within a wide spectrum of complex MV lesions. ${ }^{11-13}$ More recently, our group and others ${ }^{4-6,8}$ have reported improved results, including lower postoperative morbidity and mortality in patients undergoing MV surgery, with a much reduced incidence of MV replacement.

In our current series CMV reconstruction rather than replacement proved feasible and successful in most patients. Since January 1985, our surgical policy in the management of CMV dysplasia has uniformly been a conservative one. We are convinced that regardless of the anatomic and pathological severity of the valve dysplasia, CMV reconstructive surgery should be attempted in any infant or child, with the aim of avoiding the high incidence of early and late complications, as well as the high mortality and reoperation rates related to prosthetic valve replacement in the pediatric age group. ${ }^{14,15}$ Despite the fact that MV replacement has been reported successfully even for more severe variants of CMV anomalies for a long time, ${ }^{16}$ prosthetic CMV replacement is still associated with persistent problems (eg, hemolysis, perivalvular leak, prosthetic valve thrombosis, thromboembolism, and endocarditis) and technical difficulties (eg, the necessity of placing it in an extra-anatomic position within the supra-annular area, which is demonstrated to have worse immediate and long-term results). ${ }^{14,15,18}$

MV repair preserves the subvalvular and chordal apparatus, keeping intact the normal left ventricular geometry and function. ${ }^{17}$ In agreement with Kruithof and colleagues, ${ }^{19}$ atrioventricular valve development is a process continuing into the first months of postnatal life. Thus MV surgery should be deferred as long as the patient's condition permits clinical management to enhance the chances for a more successful and satisfactory repair. This tendency has been supported by Krishnan and associates, ${ }^{20}$ who have recently reported that delay of surgical intervention until the onset of severe symptoms in children with significant MR does not increase the risk for long-term ventricular dysfunction.

Realistically, CMV surgical repair, when performed on a severely malformed MV in infancy, remains a palliative temporary treatment. The main aim of a conservative surgical approach in severe types of CMV dysplasia is to obtain an improvement in MV function, which should ameliorate the clinical status, deferring eventual MV replacement to an older age.

In our current series perioperative mortality was $8 \%$ (7/ 93). Since our series began in 1972, the overall mortality rate reflects a wide time frame. Consequently, our analysis has identified an increased risk factor (18- and 4.7-fold, respectively) for early death and loss of sinus rhythm in those patients who underwent surgical repair before 1984 . In addition, 5 of the 7 early deaths occurred before 1984, in an era when preoperative diagnosis, surgical techniques, and postoperative treatment were less developed. After 1984 , only 2 children in the complex group with severe preoperative left ventricular dysfunction caused by left ventricular endocardial fibroelastosis died early after repair.

Several authors have identified a major risk factor for perioperative mortality in the presence of associated intracardiac lesions. ${ }^{6,21,22}$ This increased risk might be due to a more complex anatomy or to the presence of a concomitant left outflow tract obstruction, ventricular septal defect, or impaired preoperative ventricular function. For this reason, we have subdivided our population into isolated and complex groups, with the purpose of understanding whether the associated cardiac lesions were responsible for a worse outcome. Interestingly, our analysis did not demonstrate an increased risk in the complex group for early or late mortality, need for early primary surgical intervention, and reoperation on the MV. However, patients with complex CMV did demonstrate a significantly higher risk for at least 1 negative outcome at follow-up. The association of CMV disease with additional complex intracardiac lesions had a significant effect on late quality of life and repeated hospitalization. Nevertheless, the durability of CMV repair appeared to be independent of the presence of associated cardiac anomalies.

Almost half of our patients presented with prevalent MV stenosis. Despite a recent report of better outcomes for stenotic MV in comparison with dysplastic regurgitant $\mathrm{MV},{ }^{8}$ our current experience confirms our previous findings ${ }^{4,5}$ indicating that the presence of MS (or prevalent MS) is predictive of negative outcomes. In fact, the death rate in patients with MS is almost 5 times higher than that of patients with MR ( $P=.021$; OR, 4.698). The KaplanMeier actuarial survival curve also shows a lower survival rate for patients with prevalent MS. Stenosis is also associated with a higher rate of early surgical intervention $(P=.006$; OR, 7.219).

Balloon MV dilation for MS has been recently reported by McElhinney and coworkers. ${ }^{23}$ In their experience $28 \%$ of patients treated with a primary balloon dilatation had moderate-to-severe MR soon after the procedure secondary to tears of the MV, disruption of chordal structures, and/or partially flail MV leaflets, leading to an immediate $5 \%$ death rate and a further $20 \%$ death rate at 1 year of follow-up. Based on our experience, even though infants were in the 
minority $(14 \%)$ compared with the whole population, we believe that better early and long-term results can be achieved with a conservative surgical treatment of CMV during cardiac surgery that allows simultaneous repair of the associated lesions.

In our experience prevalent MR has been slightly more frequent when compared with MS, accounting for $51.6 \%$ of our patients. Reconstructive surgery for MR can be achieved by using the techniques described by Carpentier and associates. ${ }^{9}$ Occasionally, in relieving a prevalent MV stenosis, a better MV competence can also be achieved by means of an improved leaflet coaptation. The use of a Carpentier ring has been advocated by many authors, ${ }^{7}$ so as to achieve a proper CMV competence. We have used a ring annuloplasty exclusively in our early experience. Our current and previous results ${ }^{4,5}$ demonstrate the effectiveness of a mural leaflet prosthetic-less annuloplasty favoring any conservative procedure that avoids the use of prosthetic material. Scar tissue caused by sutures and the ring itself might limit proper annular growth and leaflet motion., ${ }^{4,5}$

This analysis has again shown that a parachute MV carries a significant additional risk factor for early mortality and for the need for reoperation. A recent report by Marino and associates ${ }^{24}$ concerning surgical risks related to parachute MV and conotruncal anomalies also supports our findings.

There are some limitations to this study, especially the retrospective nature of the analysis. In addition, patients were managed over a span of more than 30 years, during which time nonanatomic factors influencing outcome might have changed. However, despite this and the intrinsic palliative nature of mitral repair in this age group, we strongly advise conservative surgical intervention for any kind of MV dysplasia, especially in infants, to avoid the drawbacks of currently available prostheses and to improve quality of life in these children.

In conclusion, surgical repair of MV dysplasia in infants and children is an effective and reliable treatment with a decreasing early and late mortality and reoperation rate, even in the most complex anatomic variants. MV reconstruction needs to be carefully planned and tailored to each patient, with the aim of achieving a "physiological" repair rather than an "anatomic" one. Anatomic severity of MV malformations influences the long-term freedom from MV replacement in both the isolated and complex groups. A "true" parachute MV adds a significant risk.

We thank Dr Aldo R. Castaneda for reviewing and improving the value of the manuscript.

\section{References}

1. Carpentier A. Congenital malformations of the mitral valve. In: Stark JF, deLeval MR, eds. Surgery for congenital heart defects. Philadelphia: WB Saunders; 1994. p. 599-614.

2. Oosthoek PW, Wenink AC, Wisse LJ, Gittenberger-de Groot AC. Development of the papillary muscles of the mitral valve: morphogenetic background of parachute-like asymmetric mitral valves and other mitral valve anomalies. J Thorac Cardiovasc Surg. 1998;116:36-46.

3. Ruckman RN, van Praagh R. Anatomic types of congenital mitral stenosis; report of 49 autopsy cases with consideration of diagnosis and surgical implications. Am J Cardiol. 1978;42:592-601.

4. Stellin G, Bortolotti U, Mazzucco A, Faggian G, Guerra F, Daliento L, et al. Repair of congenitally malformed mitral valve in children. $J$ Thorac Cardiovasc Surg. 1988;95:480-5.

5. Stellin G, Padalino M, Milanesi O, Vida V, Favaro A, Rubino M, et al. Repair of congenital mitral valve dysplasia in infants and children: is it always possible? Eur J Cardiothorac Surg. 2000;18:74-82.

6. Wood AE, Healy DG, Nolke L, Duff D, Oslizlok P, Walsh K. Mitral valve reconstruction in a pediatric population: late clinical results and predictors of long-term outcome. I Thorac Cardiovasc Surg. 2005;130:66-73.

7. Chauvaud S. Congenital mitral valve surgery: techniques and results. Curr Opin Cardiol. 2006;21:95-9.

8. Oppido G, Davies B, McMullan DM, Cochrane AD, Cheung MM, d'Udekem Y, et al. Surgical treatment of congenital mitral valve disease: midterm results of a repair-oriented policy. J Thorac Cardiovasc Surg. 2008;135: 1313-20.

9. Carpentier A, Branchini B, Cour JC, Asfaou E, Villani M, Deloche A, et al. Congenital malformations of the mitral valve in children. Pathology and surgical treatment. J Thorac Cardiovasc Surg. 1976;72:854-66.

10. Bargiggia GS, Tronconi L, Sahn DJ, Recusani F, Raisaro A, De Servi S, et al. A new method for quantitation of mitral regurgitation based on color flow Doppler imaging of flow convergence proximal to regurgitant orifice. Circulation. 1991; 84:1481-9.

11. Coles JG, Williams WG, Watanabe T, Duncan KF, Sherret H, Dasmahapatra HK, et al. Surgical experience with reparative techniques in patients with congenital mitral valvular anomalies. Circulation. 1987;76:117-22.

12. McCarthy JF, Neligan MC, Wood AE. Ten years experience of an aggressive reparative approach to congenital mitral valve anomalies. Eur J Cardiothorac Surg. 1996;10:534-9.

13. Chauvaud S, Fuzellier JF, Houel R, Berrebi A, Mihaileanu S, Carpentier A. Reconstructive surgery in congenital mitral valve insufficiency (Carpentier techniques): long term results. J Thorac Cardiovasc Surg. 1998;115:84-93.

14. Caldarone CA, Raghuveer G, Hills CB, Atkins DL, Burns TL, Behrendt DM, et al. Long-term survival after mitral valve replacement in children aged $<5$ years: a multi-institutional study. Circulation. 2001;104(suppl 1):I143-7.

15. Kojori F, Chen R, Caldarone CA, Merklinger SL, Azakie A, Williams WG, et al. Outcomes of mitral valve replacement in children: a competing-risks analysis. J Thorac Cardiovasc Surg. 2004;128:703-9.

16. Castaneda AR, Anderson RC, Edwards JE. Congenital mitral stenosis resulting from anomalous arcade and obstructing papillary muscles. Report of correction by use of ball valve prosthesis. Am J Cardiol. 1969;24:237-40.

17. van Rijk-Zwikker GL, Delemarre BJ, Huysmans HA. Mitral valve anatomy and morphology: relevance to mitral valve replacement and valve reconstruction. J Card Surg. 1994;9(suppl II):255-61.

18. Selamet Tierney ES, Pigula FA, Berul CI, Lock JE, del Nido PJ, McElhinney DB. Mitral valve replacement in infants and children 5 years of age or younger: evolution in practice and outcome over three decades with a focus on supra-annular prosthesis implantation. J Thorac Cardiovasc Surg. 2008;136:954-61, e1-3.

19. Kruithof BP, Krawitz SA, Gaussin V. Atrioventricular valve development during late embryonic and postnatal stages involves condensation and extracellular matrix remodeling. Dev Biol. 2007;302:208-17.

20. Krishnan US, Gersony WM, Berman-Rosenzweig E, Apfel HD. Late left ventricular function after surgery for children with chronic symptomatic mitral regurgitation. Circulation. 1997;96:4280-5.

21. Serraf A, Zoghbi J, Belli E, Lacour-Gayet F, Aznag H, Houyel L, et al. Congenital mitral stenosis with or without associated defects: an evolving surgical strategy. Circulation. 2000;102(suppl III):III166-71.

22. Prifti E, Vanini V, Bonacchi M, Frati G, Bernabei M, Giunti G, et al. Repair of congenital malformations of the mitral valve: early and midterm results. Ann Thorac Surg. 2002;73:614-21.

23. McElhinney DB, Sherwood MC, Keane JF, del Nido PJ, Almond CS, Lock JE. Current management of severe congenital mitral stenosis: outcomes of transcatheter and surgical therapy in 108 infants and children. Circulation. 2005;112: 707-14.

24. Marino BS, Kruge LE, Cho CJ, Tomlinson RS, Shera D, Weinberg PM, et al. Parachute mitral valve: morphologic descriptors, associated lesions, and outcomes after biventricular repair. J Thorac Cardiovasc Surg. 2009;137:385-93. 